\title{
ANALYSIS OF BINOMIAL SAMPLING DATA FOR ESTIMATING THRIPS DENSITIES ON ORNAMENTAL PLANTS
}

\author{
S.P. WORNER and R.B. CHAPMAN \\ Soil Plant and Ecological Sciences Division, P.O. Box 84, \\ Lincoln University, Canterbury
}

\begin{abstract}
Compared with standard sampling methods, binomial sampling reduces the time required to assess densities of pest species. Such sampling is promoted as a practical procedure for use by non-specialists. A leaf sampling method was used to estimate the density of greenhouse thrips on a viburnum hedge at different stages of thrips population growth. Three methods were used to relate the proportion of leaves infested to the mean density of thrips. Sample size curves were calculated and compared at $10 \%$ and $25 \%$ levels of precision. The sample sizes required for density estimation at both levels of precision differed between methods. The difficulties in developing binomial sampling plans are discussed.
\end{abstract}

\section{INTRODUCTION}

Several thrips species have been shown to cause severe cosmetic damage on ornamentals such as rhododendron and viburnum. However, application of insecticides on ornamental plants in urban environments is increasingly questioned and needs to be justified by the pest occurring at damaging levels. Chapman and Worner (1999) investigated a method for sampling to estimate population density of greenhouse thrips, Heliothrips haemorrhoidalis, on a common ornamental plant, Viburnum tinus L. This study showed enumerative sampling to be time consuming and costly to implement. Because of this, counting such a small abundant arthropod species in a monitoring program for integrated pest management (IPM) may be poorly adopted by non-specialists. However, binomial or presence-absence sampling has become popular in IPM in recent years as it requires only the proportion of sample units infested with one or more individuals (incidence) to be measured. The mean population density can then be estimated from a previously determined relationship between pest incidence and density. The incidence-density relationship can then be used with an action threshold to make management decisions.

Central to the development of presence-absence sampling programs is the determination of the population dispersion of the species of interest and to account for this in the incidence-density relationship. As numerous approaches to the development of binomial sampling plans exist, the purpose of this study was to explore the performance of three approaches that have been used specifically for thrips or other small arthropods.

\section{METHODS}

A $V$. tinus hedge, approximately $90 \mathrm{~m}$ long with an average height of $3.0 \mathrm{~m}$, located on the Lincoln University campus was used. This hedge was divided into eight $5 \mathrm{~m}$ long plots. Thirty sample positions were randomly located along each plot then randomly assigned to one of three strata (lower, middle and upper levels of the hedge). A single leaf of new season's growth at each position was removed and placed in a plastic vial. Each leaf was selected by touch to avoid visual bias. The leaves were examined under a microscope in the laboratory and the number of immature and adult thrips counted on each leaf. The proportion of leaves infested in each plot was also 
recorded. To record changes in incidence with changes in density as the thrip population increased, sampling was carried out on seven occasions between 5 October 1998 and 12 February 1999.

\section{Analysis}

The data obtained from the eight plots and seven sampling occasions were combined to give 56 data points. Analysis of the data using Loyd's index of patchiness (I) (Davis 1994) and k, the parameter of the negative binomial distribution, indicated that the dispersion of the thrips population was aggregated (Chapman and Worner 1999). One of the most widely used methods to determine the population dispersion of insects is Taylor's power law (TPL). Taylor's power law relates $\mathrm{s}^{2}$ to $\mathrm{x}$ by $\mathrm{s}^{2}=\mathrm{ax}^{\mathrm{b}}$ where $b$ is an index of dispersion. Values of $b>1$ indicate aggregated dispersion, $b=1$ random dispersion and $\mathrm{b}<1$ regular dispersion. The parameters of TPL are usually estimated from the regression equation: $\log \mathrm{s}^{2}=\log \mathrm{a}+\mathrm{b} \log \mathrm{x}$. In this study, three approaches were used to relate percentage infestation to thrips density (mean thrips per leaf), 1) the Wilson and Room (1983) equation, based on the negative binomial distribution but constrained to follow the TPL model, 2) mean densities were transformed using $\mathrm{x}^{1-0.5 \mathrm{~b}}$ (Southwood 1978) to obtain a linear relationship with percent infestation (Steiner 1990) and 3) the widely used equation of Kono and Sugino (1958) (K-S equation) and Gerrard and Chiang (1970) which does not require any assumption about an underlying theoretical distribution (Mailloux and Bostanian 1989). To fit the linear form of the TPL equation, $\log (x+1)$ transformation was used to avoid infinite values for zero counts. To fit the linear form of the K-S equation, zero counts were removed from the data set.

The Ruesink (1980) equation based on Taylor's power law was used to calculate the number of sample units required to estimate mean density of thrips at 10 and $25 \%$ levels of precision (fraction $d$ of $\mathrm{x}$ ) for methods 1 (Steiner 1990) and 2 (Wilson and Room 1983). The general formulā (Ruesink 1980) was used to determine the sample size required to estimate mean density of thrips for the K-S equation. Two methods, one proposed by Jones (1994) and one by Kuno (1986), to approximate the variance of a mean (Var (m)) for the K-S equation, were compared. $\operatorname{Var}(\mathrm{m})$ multiplied by the sample size, $n$, was used to approximate $\mathrm{s}^{2}$ for the Ruesink general equation.

\section{RESULTS}

Taylor's power law fitted the data well $\left(\mathrm{P}<0001, \mathrm{R}^{2}=0.93\right)$. The parameters were estimated as $a=0.985$ and $b=1.9569$. These parameters were used for both the Steiner method and the Wilson and Room equation to derive incidence-density relationships. The K-S equation also fitted the data well $\left(\mathrm{P}<0.0001, \mathrm{R}^{2}=0.89\right)$. The relationship between percentage leaves infested and the mean number of thrips per leaf for all three

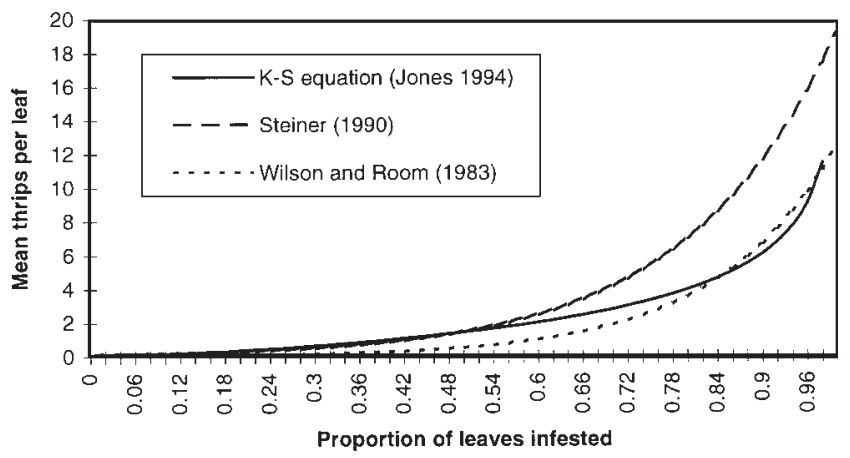

FIGURE 1: Predicted mean densities. Incidence-density curves for thrips on viburnum leaves using three methods of analysis. 




FIGURE 2: Sample size curves to estimate mean densities of thrips within a precision level of $25 \%$. The Steiner and Wilson and Room curves coincide. Curves for the K-S equation were generated using two different variance estimates.

methods of analysis are shown in Fig. 1. The Steiner method gives higher predicted mean densities at high levels of infestation (above 60\%) compared with the other two methods. The Wilson and Room and K-S methods predict densities similar to each other throughout the full range of percentage infestation but lower than the Steiner method when more than $60 \%$ of leaves are infested.

For the $10 \%$ level of precision, sample sizes required for all methods were extremely large. For this reason, only the results for the $25 \%$ level (considered practical for pest management sampling programs) are shown. Because the same TPL parameter (b) was used in the Ruesink (1980) equation, the curves for the sample sizes required to estimate mean thrips density for the Steiner method and Wilson and Room equation, correspond (Fig. 2). Large differences were found between the Steiner/ Wilson and Room sample size curve and those (using differing variance estimates) for the K-S equation. Sample sizes required for the K-S methods differed greatly and were considerably larger than the Steiner/Wilson and Room methods.

\section{DISCUSSION}

The differences in the predicted mean densities (Fig. 1) would not be important in the thrips/viburnum system studied here. While an action threshold has not yet been established, casual observation (Chapman and Worner 1999) suggests that it would be very low, probably less than three thrips per leaf and therefore located where the confidence intervals for prediction for the three curves are likely to overlap. However, such differing results may be accentuated in other host/plant systems where an action threshold at a higher densities may result in incorrect decisions.

Such large differences in the sample size curves for the methods used in this study are difficult to explain. The most likely explanations are the underestimation of the true variance in the Steiner and Wilson and Room methods (also see Navaset al. 1994) and the difference in the components of the two variance approximations used for the $\mathrm{K}-\mathrm{S}$ equation. Variance estimates need to take into account both the variance 
associated with estimating a proportion and the variance predicting the mean from a proportion (Jones 1994).

Of all analyses, the Steiner method was the easiest to implement but the method has not been well tested and may be questioned on theoretical grounds. The K-S equation is widely used but, as with all methods in this study, problems associated with variance approximations need to be resolved (Nyrop and Binns 1991).

Clearly, the development of binomial sampling plans is not easy. The usual guideline of using what fits the data best is no reason for complacency in this area. For those attempting to develop binomial sampling plans, the advice is to proceed with caution.

\section{REFERENCES}

Chapman, R.B. and Worner, S.P., 1999. Sampling thrips on ornamental plants. Proc. 52nd N.Z. Plant Prot. Conf.: 36-39.

Davis, P. M., 1994. Statistics for describing populations. Pp 33-54 In: Handbook of Sampling Methods for Arthropods in Agriculture, L.P. Pedigo and G.D. Buntin (Eds); CRC Press, Boca Raton.

Gerrard, D.J. and Chiang, H.C., 1970. Density estimation of corn rootworm egg populations based upon frequency of occurrence. Ecology 51: 237-245.

Jones, V. P., 1994. Sequential estimation and classification procedures for binomial counts. Pp 175-205 In: Handbook of Sampling Methods for Arthropods in Agriculture, L.P. Pedigo and G.D. Buntin (Eds); CRC Press, Boca Raton.

Kono, T. and Sugino, T., 1958. On the estimation of density of rice stem infested by the rice stem borer. Japanese J. Appl. Entomol. and Zool. 2: 184.

Kuno, E., 1986. Evaluation of statistical precision and design of efficient sampling for the population estimation based on frequency of occurrence. Res. Pop. Ecol. 28: 305-319.

Mailloux, G. and Bostanian, N.J., 1989. Presence-absence sequential decision plans for management of Lygus lineolaris (Hemiptera: Miridae) on strawberry. Environ. Entomol. 18: 829-834.

Navas, V.E., Funderburk, J.E., Mack, T.P., Beshear, R.J. and Olson, S.M., 1994. Aggregation indices and sample size curves for binomial sampling of flowerinhabiting Frankliniella species (Thysanoptera: Thripidae) on tomato. J. Econ. Ent. 87: 1622-1626.

Nyrop, J.P. and Binns, M.B., 1991. Quantitative methods for designing and analysing sampling programs for use in pest management. Pp 67-132 In: Handbook of Pest Management in Agriculture, D. Pimental (Ed.); CRC Press, Boca Raton.

Ruesink, W.G., 1980. Introduction to sampling theory. Pp 61-78 In: Sampling Methods in Soybean Entomology, M. Kogan and D.C. Herzog (Eds.); Springer Verlag, New York.

Southwood, T.R.E., 1978. Ecological methods with particular reference to the study of insect populations. Halsted Press, New York. 391 pp.

Steiner, M.Y., 1990. Determining population characteristics and sampling procedures for the Western flower thrips (Thysanoptera: Thripidae) and the predatory mite Amblyseius cucumeris (Acari: Phytoseiidae) on greenhouse cucumber. Environ. Entomol. 19: 1605-1603.

Wilson, L.T. and Room, P.M., 1983. Clumping patterns of fruit and arthropods in cotton, with implications for binomial sampling. Environ. Entomol. 12: 50-54. 